\title{
Hybrid Intelligent Technique (SFLA-PSO) for Control and Intellectual Process of Power System with Huge Penetration of Non-Conventional Energy Sources
}

\author{
Divya S., S. B. Shivakumar, T. Ananthapadmanabha
}

\begin{abstract}
Due to the pressure of decreasing the carbon emission and inadequate sources of fossil fuels being a major reason, Renewable Energy is being incorporated rapidly throughout the globe. Smart grids have a substantial prospective towards tapping the non-conventional energy sources in their grid-connected mode or stand-alone mode [2]. Such limited systems across the sectarian domains of distributed generation systems despite the fact of tapping non-conventional energy sources, stay expected to be the advanced networks which may assist in transmuting the power and energy segment through not only delivering energy to distant and isolated communities, but also through better safekeeping and dependability of electrical energy resource in the urban zones [2][3].

Predominantly, due to a very large or bulk dispersion of non-conventional energy, the system units are expected to practice substantial encounters in sheltered and steady state process, very prominently on advanced stages of inconstant and spasmodic non-conventional sources (solar and wind).

This paper is aimed to investigate the influence of the distributed generation like Wind and $P V$ on the power system due to the large diffusion of non-conventional sources.
\end{abstract}

Keywords: Non-Conventional Energy Sources, Uncertainty, penetration level, optimization techniques, Constraints, Optimal location.

\section{INTRODUCTION}

In the preceding few years, electrical energy resource and the quality of power supply has accomplished collective attention as they are the vital centers for modern-day life. Currently mentioned to as a product with a defined quality, electrical energy supply is rather an irreplaceable invention because of its intangible and transient character [3].

Revised Manuscript Received on February 05, 2020.

* Correspondence Author

Mrs. Divya S., Department of Power Systems Engineering, Stream National Institute of Engineering, Mysuru, Karnataka, India.

Dr. T. Anathapadmanabha, Ph.D., Department of Power Systems Engineering, Stream National Institute of Engineering, Mysuru, Karnataka, India.

Dr. S. B. Shivakumar, HOD, Department of Electrical and Electronics, RYMEC, Bellary, Karnataka, India.

(c) The Authors. Published by Blue Eyes Intelligence Engineering and Sciences Publication (BEIESP). This is an open access article under the CC BY-NC-ND license (http://creativecommons.org/licenses/by-nc-nd/4.0/)
Through the liberalization of electrical energy marketplaces and the accumulative dissemination of Distributed Generation from Renewable Energy Sources (RES) determined by promising ecological guidelines and supervisory backgrounds, apprehensions have been raised up concerning the influences on the quality of resource [2].

\section{DISTRIBUTED GENERATION AND ITS IMPACT}

Distributed Generation is an adequate production or storing of electrical energy at the consumer end, that certificates the choice of transferring and importing energy to the utility system and vice versa, however captivating benefit of the Extreme productivity of electrical power production [10]. Basically, the capability range of dispersed generation is between $100 \mathrm{~kW}$ to $10 \mathrm{MW}$. Figure 1.1 shows the various DG Technologies that are in use.

The interface of DG with the grid can be categorized into two types [14]:

a. Direct grid-connected DGs- Direct-connected DGs are attained with the help of induction or synchronous generator. The prime mover functions at a consistent speed to drive the generators.

b. Indirect grid-connected DGs - Indirect grid connection is used when the output of the source is DC (for example PV systems and fuel-cells), high frequency AC (for example micro-turbines) and variable frequency (such as WECS).

Even though the incorporation of the DG into electric power systems has assorted benefits, they increase the complication [15]. As a result, the DGs affect the system performance such as voltage characteristics, system power flow, losses in the system, power quality, steady state stability, reliability, and protection.

\section{POWER SYSTEM OPTIMIZATION TECHNIQUES:}

\section{A.Shuffled Frog Leap Algorithm :}

SFLA is a Meta heuristic optimisation technique which imitates the memetic progression of a set of frogs while looking out for the locality which contains extreme volume of accessible foodstuff. The SFLA comprises components of local and global search and interchange of information [10]. 
The SFLA comprises a populace of potential results which are defined by a number of virtual frogs (set) which are divided into smaller number of frogs(sub sets) referred to as memeplexes. Inside every memeplex, the specific frog has an idea that can be affected by the ideas of other frogs, and these ideas can develop by means of memetic evolution.
To make sure the global investigation, after a definite number of memeplex development phases (local hunt), where the virtual frogs are scuffled and restructured to form fresh memeplexes [11]

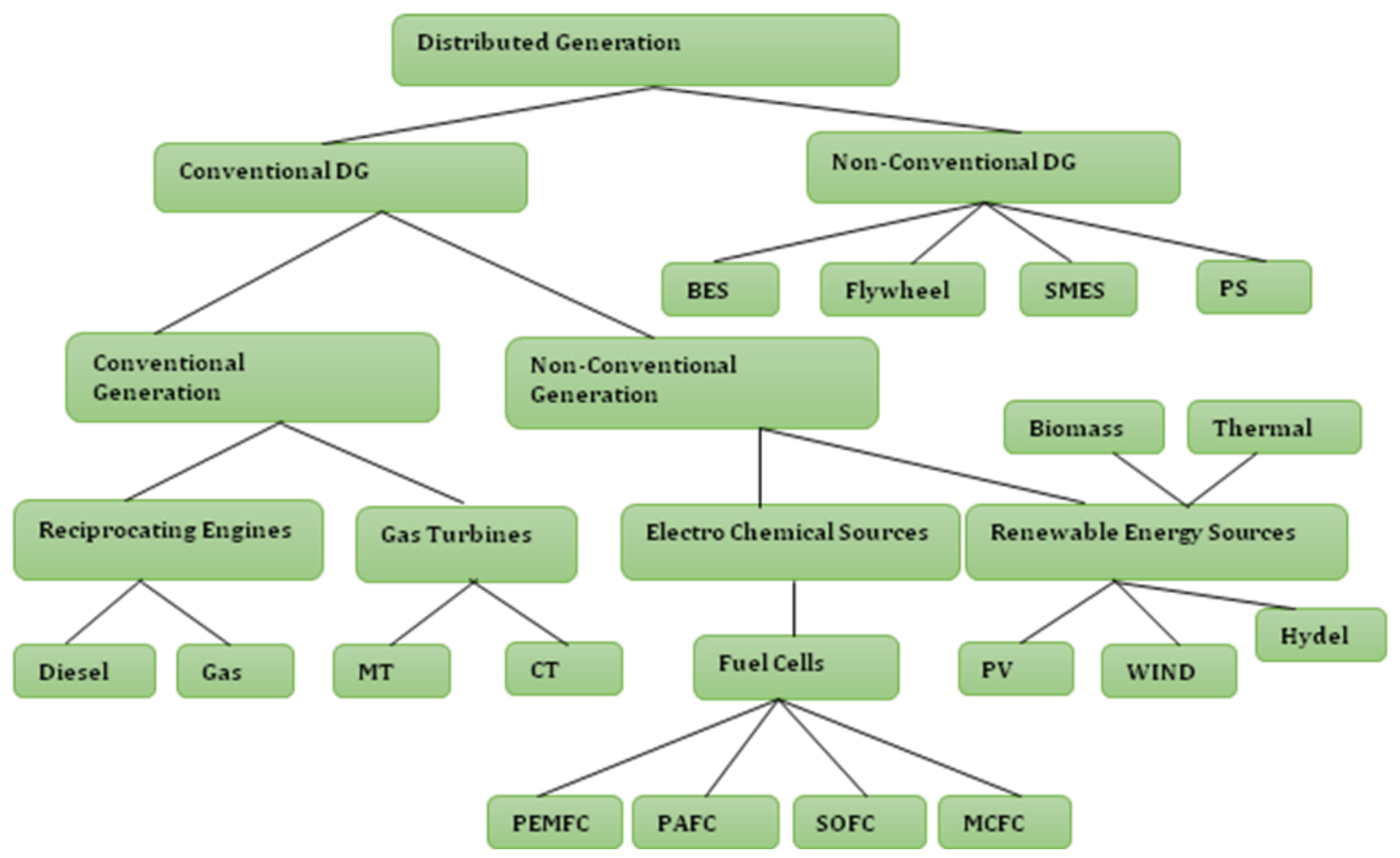

Figure 1.1: Different types of DG Technologies

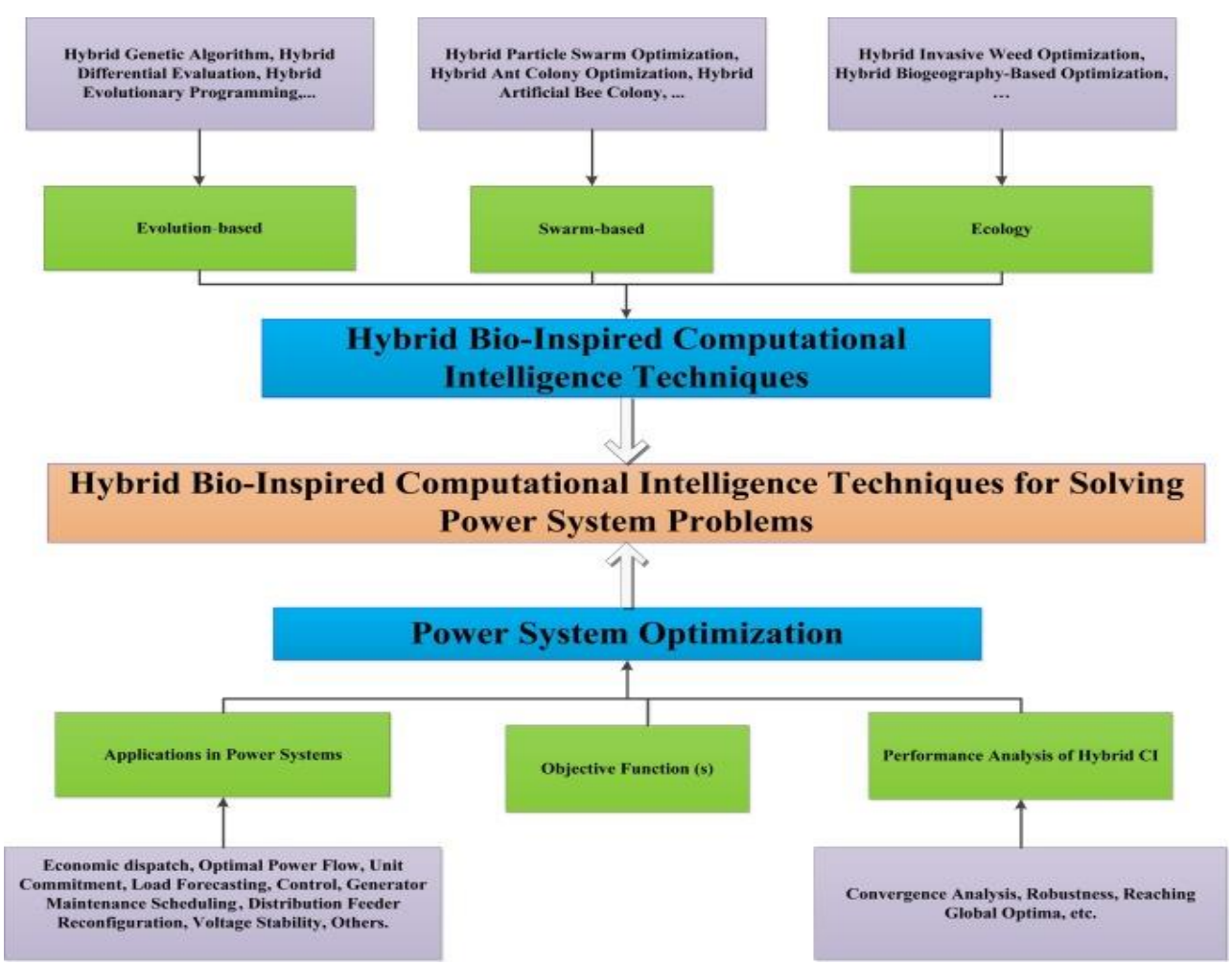

Figure 1.2: Types of Power system optimization techniques

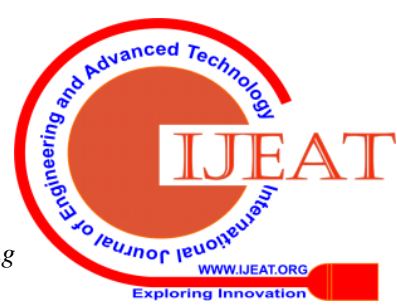




\section{Biologically Inspired algorithms}

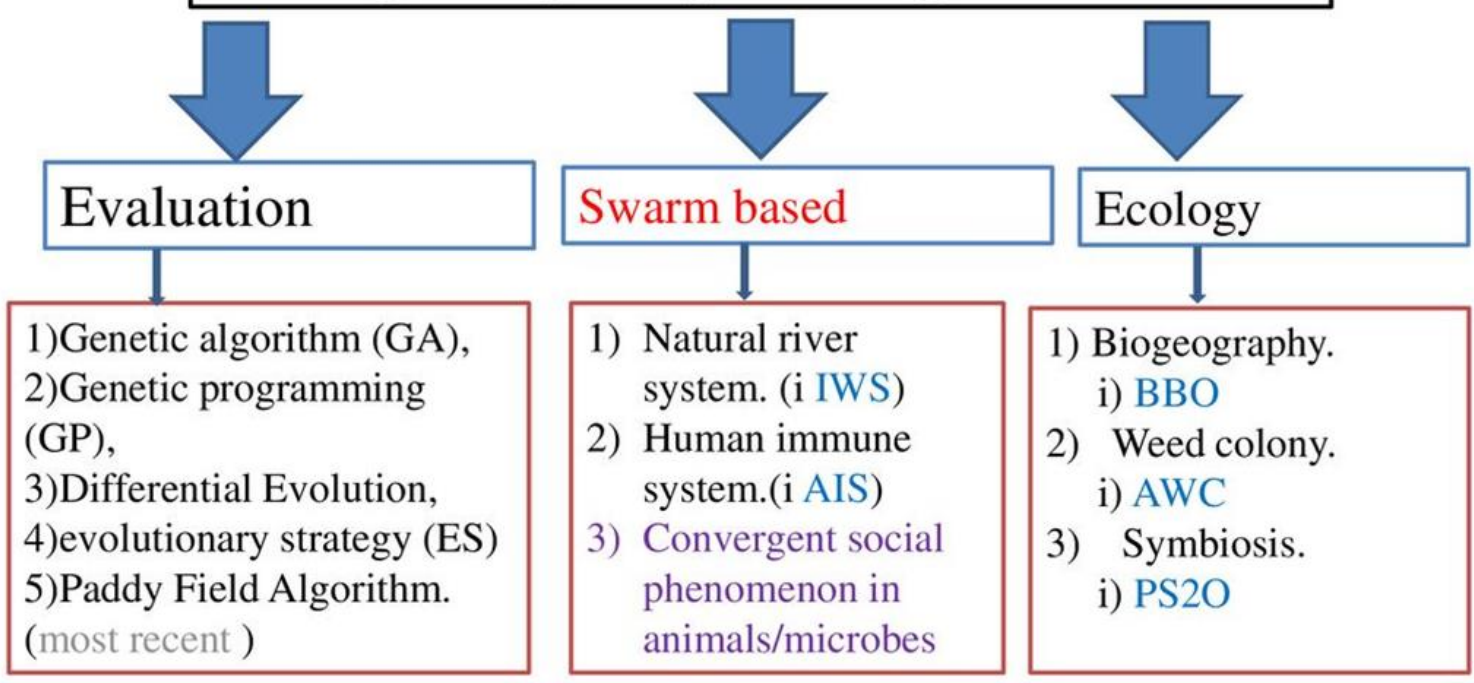

Convergent phenomenon in animals/microbes

1) Producer scrounger.

- Group Search Optimization(GSO).

2) Bird flocking .

- Practical Swarm Optimization(PSO).

3) Stigmergy.

- Ant colony optimization(ACO).

4)Fish schooling.

- Fish Swarm Optimization(FSO).

5) Bacterial foraging.

- Bacterial Foraging Algorithms(BFA).

6) Fire fly.

- Fire fly algorithms(FA).

7) Social Behavior of bees.

- Artificial bee Colony (ABC).

8) Frog leaping.

- Shuffled Frog Leaping Algorithm(SFLA)

Figure 1.3: Types of biologically inspired Power system optimization techniques

Also along with this, in order to afford chance for random generation of better statistics, random virtual frogs are created and replaced in the populace if the local search fails to obtain better solutions.

The local hunt and the shuffling procedure will carry on till a definite convergence condition is fulfilled. After a definite quantity of memetic evolution stages, the ideas are handed over to the other memeplexes in a scuffling procedure. Figure 1.4 illustrates the flow chart of SFLA[11]

Possible Solutions $F=m * n$ are randomly separated or divided into numerous memeplexes $(m)$, every memeplex comprising of equivalent amount of results ( ).
All memeplexes will be evolved independently. Firstly, a primary populace of $F$ frogs is formed arbitrarily amongst the possible region. For a problem with $\mathrm{R}$ variables, the $i$ th frog is denoted as $X i=(x i 1, x i 2 \ldots x i R)$. Later, the frogs are organized according to descendent order with respect to their fitness. Later, the whole populace $(F)$ will be divided into $m$ memeplexes, totally containing $n$ frogs. In this process, the $1^{\text {st }}$ frog travels to the $1^{\text {st }}$ memeplex, the $2^{\text {nd }}$ frog travels to the $2^{\text {nd }}$ memeplex, $m^{\text {th }}$ frog travels to the $m^{\text {th }}$ memeplex, and frog $m+1$ travels back to the $1^{\text {st }}$ memeplex, etc[09] 
Hybrid Intelligent Technique (SFLA-PSO) for Control and Intellectual Process of Power System with Huge Penetration of Non-Conventional Energy Sources

Inside every memeplex, location of frogs with the finest (best) and poorest (worst) finesses is identified as $X b$ and $X w$, correspondingly. Along with this the location of a frog with the universal (global) fitness is identified as $\mathrm{Xg}$. Later, in every memeplex, a specific method is used to improve the frog with the lowest fitness in every sequence as shown:

$$
\begin{gathered}
\mathrm{D}_{\mathrm{i}}=\operatorname{Rand}() \times\left(\mathrm{X}_{\mathrm{b}}-\mathrm{X}_{\mathrm{W}}\right) \\
\mathrm{X}_{\mathrm{W}_{\text {NEW }}}=\mathrm{X}_{\mathrm{W}}+\mathrm{D}_{\mathrm{i}}
\end{gathered}
$$

Where $R_{\text {and }}$ ( ) is some arbitrary numeral between 0 and 1 . Once this procedure produces a improved result, the worst frog will be switched.

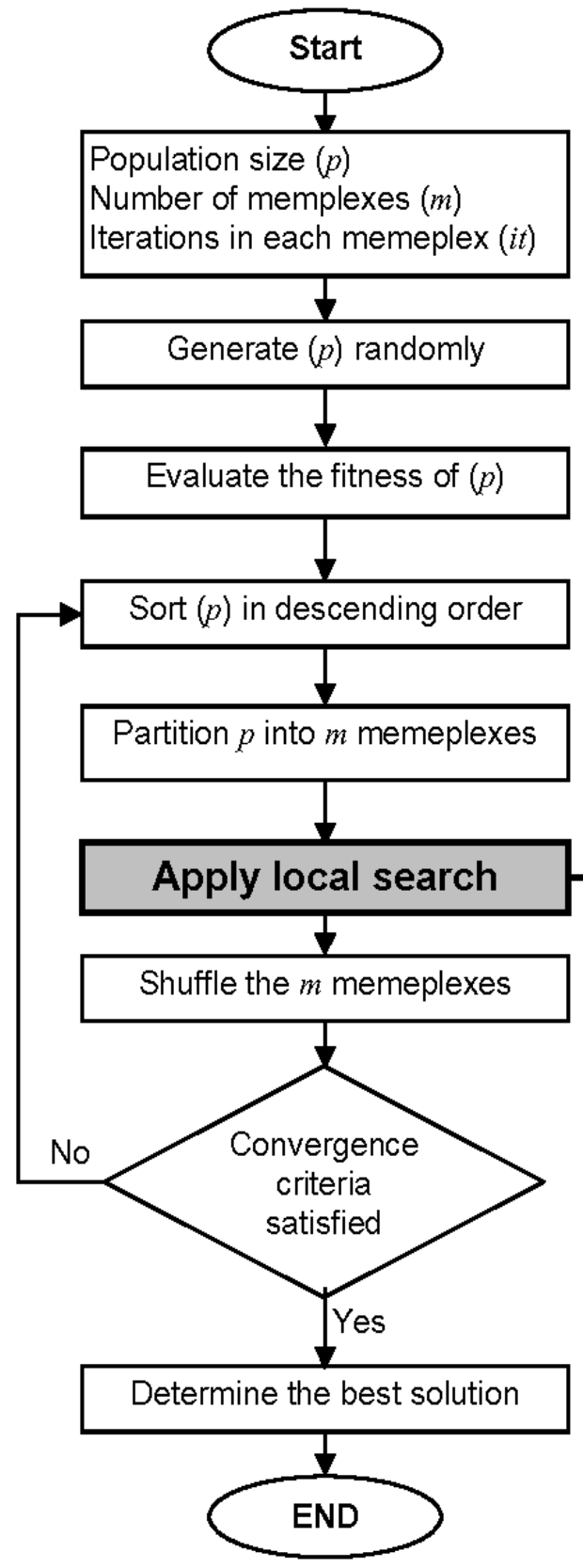

a

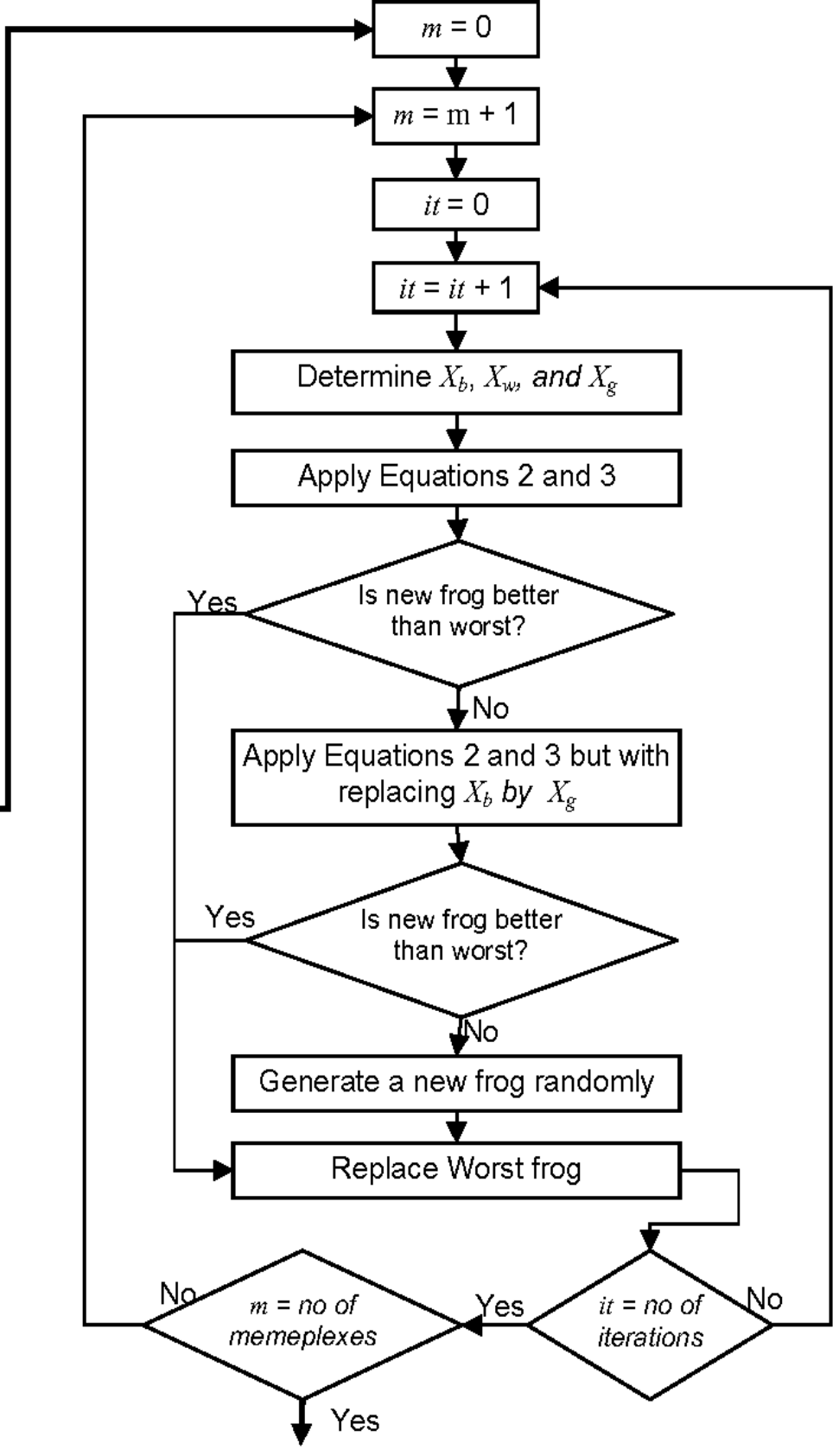

$\mathbf{b}$

Figure 1.4 : SFLA Algorithm with steps

Else, the above steps with calculations are repeated with exchange of $\mathrm{X}_{\mathrm{b}}$ by $\mathrm{X}_{\mathrm{g}}$. If there is no improvement in this step, then a fresh result is arbitrarily produced inside the possible space to change the worst frog. Later, the same steps will carry on for a certain number of iterations To make sure the global exploration; after a certain number of memetic evolution steps inside each memeplex, the ideas that were passed within memeplexes will be pooled up in the scuffling process [17] 


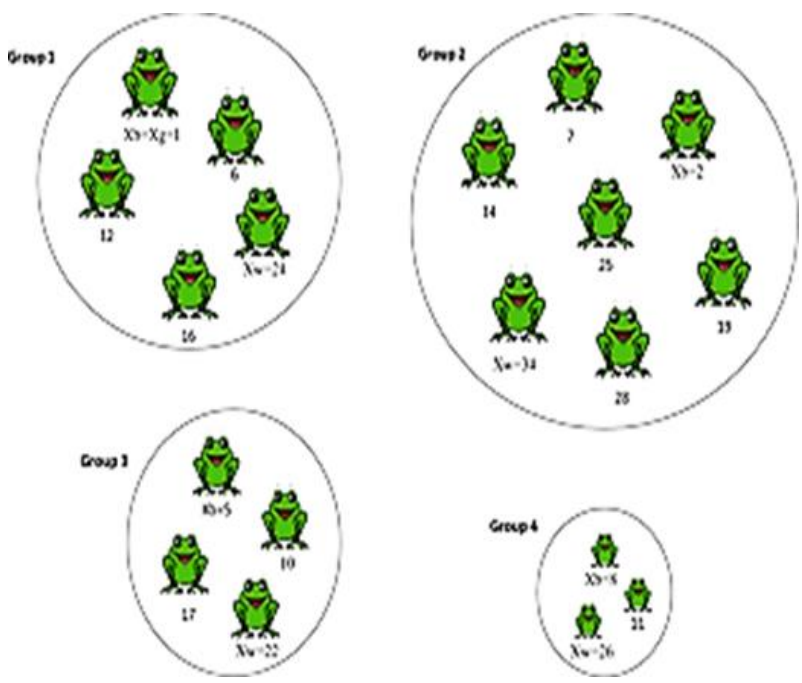

Figure 1.5: Memeplexes and grouping of frogs

\section{B.Particle Swarm Optimization Technique:}

PSO is an extensively used optimization technique that is based on swarm intelligence, where in the hunt is made on the basis of the speed of particle. The PSO is a populace based searching process that utilizes the particles to adjust their location in the problem space, which is as shown below:[13] $V_{i}^{k+1} \omega^{k} V_{i}^{k}+a_{1} r_{1} \times\left(P_{b i}^{k}-X_{i}^{k}\right)+a_{2} r_{2} \times\left(G_{b i}^{k}-X_{i}^{k}\right)$ Where $\mathrm{P}_{\mathrm{bi}}$ signifies the local best particle, $\mathrm{G}_{\mathrm{bi}}$ designates the global best particle, $\omega$ designates the inertia weight function, $a_{1}$ and $a_{2}$ denote the acceleration constants and $r_{1}$ and $r_{2}$ are the arbitrary random values that lie between 0 and 1.

The particle's location is reorganized as given:

$$
X_{i}=X_{i}+v_{i} \text {. }
$$

The procedure of PSO is given as below

Step 1: Input the system parameters such as wind specification, voliage limit, line data, bus data and line limits;

Step 2: Initialize the PSO settings;

Step 3: Set the iteration counter $c=0$, where the population of particles is initialized with random positions and velocities on dimensions;

Step 4: For each particle, the objective function is calculated and compared with the individual best value. Based on this, the best $P_{b}$ value is modified with the higher value, and the current position of the particle is recorded;

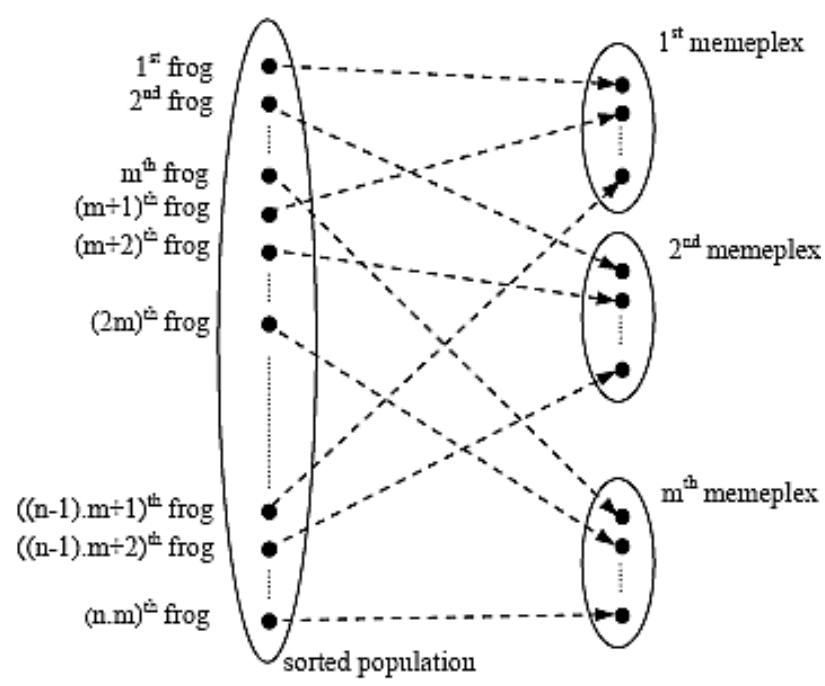

Step 5: Choose the particle that associated with the individual best $P_{b}$ of all particles, and set the value of $P_{b}$ as the overall $G_{b}$;

Step 6: Update the velocity and position of each particle;

Step 7: If the number of iterations reach the maximum limit. go to Step 8; otherwise, set the iteration index as $c=$ $c+1$ and go to Step 4;

Step 8: The best particle denoted by $G_{b}$ provides the optimal solution for the problem;

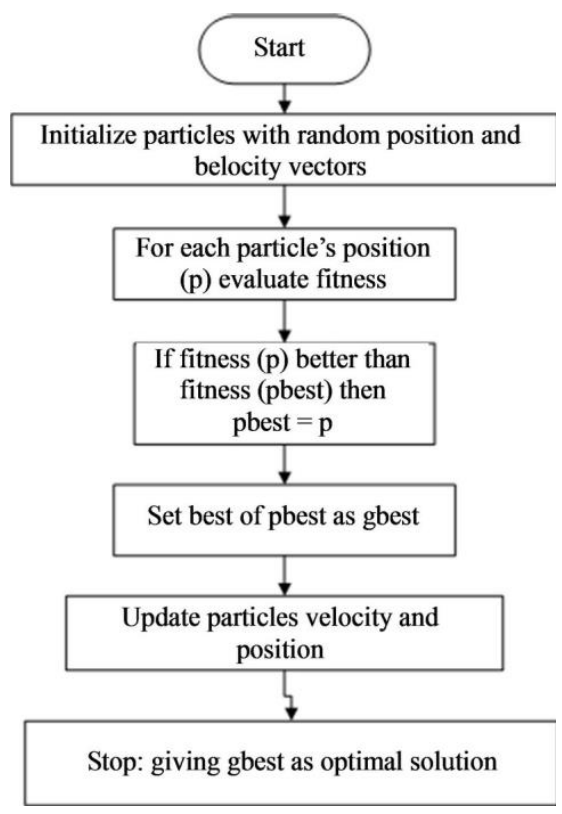

Figure 1.6: Flowchart of PSO [13] 
The rapidity and locations of particles are updated using the below Equations:

$$
v_{i}=w v_{i}+c_{1} \cdot r_{1} \cdot\left(P_{i}-X_{i}\right)+c_{2} \cdot r_{2} \cdot\left(P_{g}-X_{i}\right),
$$

$$
\begin{gathered}
w=\frac{2}{\varphi 2} \sqrt{\varphi^{2}} 4 \varphi \\
\varphi=\varphi_{1}+\varphi_{2} \\
c_{1}=w \varphi_{1} \\
c_{2}=w \varphi_{2}
\end{gathered}
$$

Here, $v_{i}$ is the speed of the ith particle; $r_{1}$ and $r_{2}$ are two arbitrary quantities which assures an identical dispersal in $0-1 ; \mathrm{X}_{\mathrm{i}}$ and $\mathrm{P}_{\mathrm{i}}$ are existing location and particular top location, correspondingly[23];

$\mathrm{P}_{\mathrm{g}}$ is the global best location; and $\phi_{1}$ and $\phi_{2}$ both are set as 2.05. The flight speed of the particles is restricted by $\mathrm{V}_{\max }$, which is given by:

$$
v_{\max }=\left(X_{\max }-X_{\min }\right) / 10 \text {, }
$$

Where $\mathrm{Xmin}$ and $\mathrm{X}_{\max }$ are the minimum and maximum constraints

The restructured speed is further combined with the existing location $\mathrm{n}$ order to attain a fresh location

\section{CASE STUDY:}

The hybrid SFLA-PSO algorithm technique is applied to the standard IEEE 33 bus system which is operated at $12.6 \mathrm{kV}$ voltage level and contains 33 busses with 32 branches. $3715 \mathrm{~kW}$ and $2300 \mathrm{kVar}$ is the total active and reactive power of the system. Fig 1.7 shows the network considered.

In this case, the results obtained after the execution of a new shuffled frog leap algorithm and particle swarm optimization algorithm is done on the IEEE 33 bus system in MATLAB. For the test system, the following circumstances are considered:

Case -1 : Allocation of Hybrid (Solar and Wind) DG unit Scenario $1: 10 \%$ Penetration of DG

Scenario $2: 30 \%$ Penetration of DG

Scenario 3 : 50 \% Penetration of DG

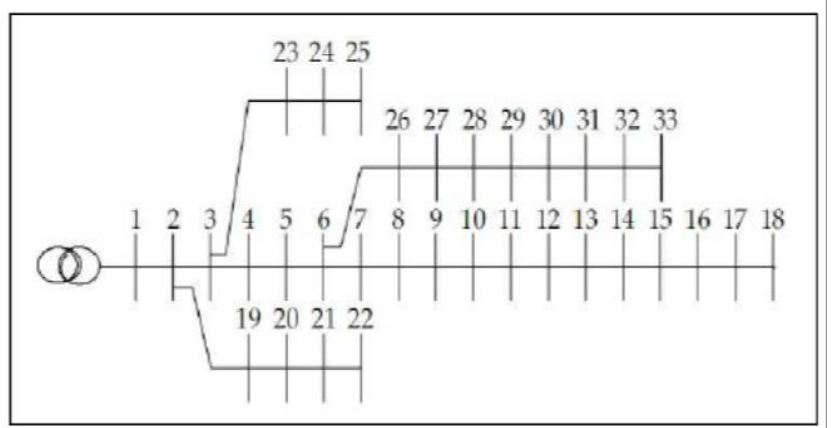

Fig 1.7 : Single line diagram of IEEE 33 bus

\section{RESULTS AND DISCUSSIONS:}

\section{A. Scenario-1: $10 \%$ Integration Of SOLAR, WIND Hybrid DG}

The results obtained from SFA-PSO algorithm for allocation of Hybrid DG unit for scenario-1 are tabulated in table 1.1.

\begin{tabular}{|c|c|}
\hline Parameters & $\begin{array}{c}\text { Hybrid Algorithm } \\
\text { Result }\end{array}$ \\
\hline 1. Optimal location & Bus 16, 32 \\
\hline 2. DG magnitude & $\begin{array}{c}752 \mathrm{KW}, \\
382.6 \mathrm{KW}, \\
-69.12 \mathrm{KVAR}\end{array}$ \\
\hline 3. Base case power loss & $201.98 \mathrm{~kW}$ \\
\hline 4. Power losses with DG & $105.76 \mathrm{~kW}$ \\
\hline 5. power loss reduction in $\%$ & 47.95 \\
\hline 6. Minimum voltage without DG & $0.90893 \mathrm{pu}$ (Bus 18) \\
\hline 7. Minimum voltage with DG & $0.9382 \mathrm{pu}$ (bus 33) \\
\hline
\end{tabular}
The system losses reduced to $105.76 \mathrm{KW}$ from $201.98 \mathrm{KW}$ and losses in percentage are reduced to $47.95 \%$. Figure 1.8 shows the deviation of voltage and power losses at all the buses before and after integration of $10 \%$ of hybrid DG.

Table 1.1: Allocation of Hybrid DG for scenario 1
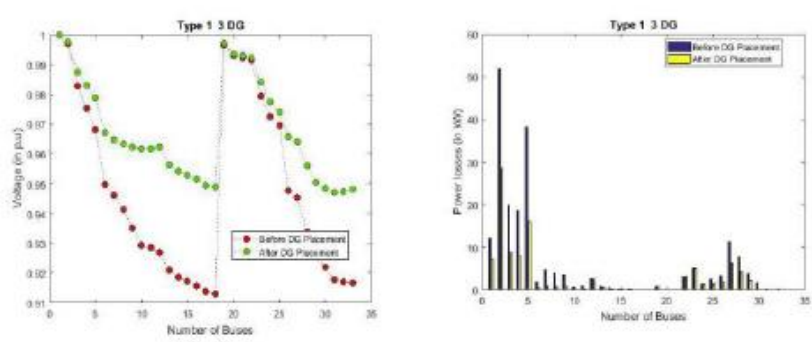

Figure 1.8: voltage and power losses at all the buses before and after integration of $10 \%$ of hybrid DG.

\section{B. Scenario-2: 30 \% Integration Of SOLAR, WIND Hybrid DG}

The results obtained from SFA-PSO algorithm for allocation of Hybrid DG unit for scenario-2 are tabulated in table 1.1. The system losses reduced to $99.94 \mathrm{KW}$ from $201.98 \mathrm{KW}$ and losses in percentage are reduced to $59.46 \%$. Figure 1.9 shows the deviation of voltage and power losses at all the buses before and after integration of $30 \%$ of hybrid DG. Table 1.2: Allocation of Hybrid DG for scenario 2

\section{Table 1.2: Allocation of Hybrid DG for scenario 2}

\begin{tabular}{|l|c|}
\hline \multicolumn{1}{|c|}{ Parameters } & Hybrid Algorithm Result \\
\hline 1: Optimal location & Bus 29, 32 \\
\hline 2: DG magnitude & $\begin{array}{c}1394 \mathrm{KW}, \\
1394 \mathrm{KW}\end{array}$ \\
\hline 3: Base case power losses & $201.98 \mathrm{KW}$ \\
\hline 4: Power losses with DG & $99.94 \mathrm{~kW}$ \\
\hline 5: Power loss reduction in \% & 59.46 \\
\hline 6: Minimum voltage without DG & 0.90893 (Bus 18) \\
\hline 7: Minimum voltage with DG & 0.9491 (Bus 33) \\
\hline
\end{tabular}



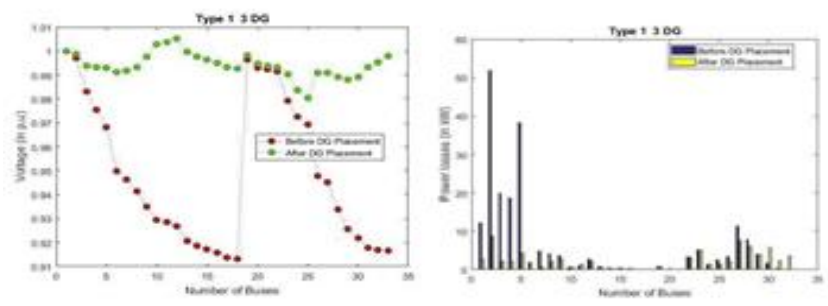

Figure 1.9: voltage and power losses at all the buses before and after integration of $30 \%$ of hybrid DG.

\section{Scenario-3: $50 \%$ Integration Of SOLAR, WIND Hybrid DG}

The results obtained from SFA-PSO algorithm for allocation of Hybrid DG unit for scenario-3 are tabulated in table 1.3. The system losses reduced to $85.96 \mathrm{KW}$ from $201.98 \mathrm{KW}$ and losses in percentage are reduced to $62.84 \%$. Figure 1.10 shows the deviation of voltage and power losses at all the buses before and after integration of $50 \%$ of hybrid DG.

Table 1.3: Allocation of Hybrid DG for scenario 3

\begin{tabular}{|l|c|}
\hline \multicolumn{1}{|c|}{ Parameters } & Hybrid Algorithm Result \\
\hline 1: Optimal location & Bus 23, 06 \\
\hline 2: DG magnitude & $\begin{array}{c}1675.6 \mathrm{KW}, \\
1675.6 \mathrm{KW}, \\
-985.6 \mathrm{KVAR}\end{array}$ \\
\hline 3: Base case power losses & 201.98 \\
\hline 4: Power losses with DG & 85.96 \\
\hline 5: Power loss reduction in \% & 62.84 \\
\hline 6: Minimum voltage without DG & 0.90893 (Bus 18) \\
\hline 7: Minimum voltage with DG & 0.95764 (Bus 33) \\
\hline
\end{tabular}
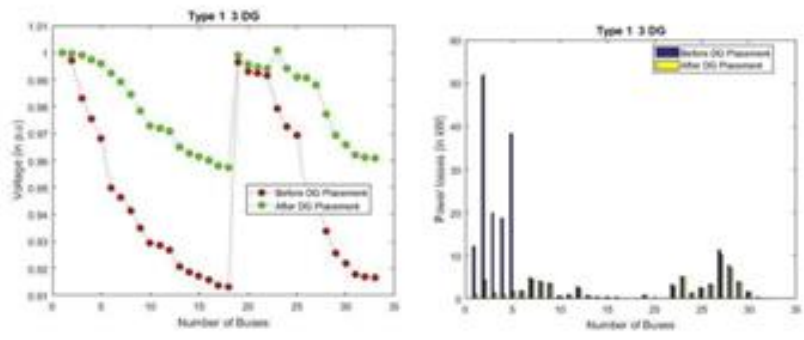

Figure 1.10: voltage and power losses at all the buses before and after integration of $50 \%$ of hybrid DG.

\section{CONCLUSION:}

In this paper a new hybrid algorithm is developed for outlining the optimal locations and penetration level based on various circumstances. The investigation is carried out for optimal position of DG for the corresponding penetration level assuming the normal operation of the system. The test system is investigated to decrease the real power losses in the system and to improve the voltage profile of the network. The process is coded in MATLAB software and the algorithms is tested on the standard IEEE 33 bus test system for hybrid solar/wind DG's

\section{REFERENCES}

1. J. Kennedy, R. Eberhart, Particle swarm optimization. in Proc. IEEE
Int. Conf. Neural Networks, 4 (1995), pp. 1942-1948

2. E. Elbeltagi, et al. Comparison among five evolutionary-based algorithms. Advanced Engineering Informatics, 19 (2005), pp. 43-53

3. Y.D. Valle, et al. Particle swarm optimization: basic concepts, variants and applications in power systems. IEEE Trans. Evol. Comput., 12 (2008), pp. 171-195

4. Y. Shi, R. Eberhart. A modified particle swarm optimizer. in Proc. IEEE World Congr. Comput. Intell, (1998), pp. 69-73

5. Mingxiao Zhu 1,* ID , Jiacai Li 1, Dingge Chang 2, Guanjun Zhang 2 and Jiming Chen 1, Optimization of Antenna Array Deployment for Partial Discharge Localization in Substations by Hybrid Particle Swarm Optimization and Genetic Algorithm Method, Energies 2018, 11, 1813; doi:10.3390/en11071813

6. Weizhe Zhang 1 ,*, Hui He 1 , and Xuehui Wang 1, Solving Energy-Aware Real-time Tasks Scheduling Problem with Shuffled Frog Leaping Algorithm on Heterogeneous Platforms, sensors, ISSN 1424-8220 www.mdpi.com/journal/sensors.

7. Rasoul Azizipanah-Abarghooeea,*, Mohammad Rasoul Narimania, Bahman Bahmani-Firouzia and Taher Niknamb, Modified shuffled frog leaping algorithm for multi-objective optimal power flow with FACTS devices, Journal of Intelligent \& Fuzzy Systems 26 (2014) 681-692 DOI:10.3233/IFS-120759 IOS Press

8. Deepak Rai and Kirti Tyagi, Bio-Inspired Optimization Techniques A Critical Comparative Study, ACM SIGSOFT Software Engineering Notes, DOI: 10.1145/2492248.2492271, http://doi.acm.org/10.1145/ 2492248.2492271

9. Saeid Jalilzadeh1, M.Sabouri2, Erfan.Sharifi3, Optimal Capacitor Placement in a Radial Distribution System using Shuffled Frog Leaping and Particle Swarm Optimization Algorithms, ACEEE Int. J. on Network Security , Vol. 03, No. 02, April 2012, ( 2012 ACEEE DOI: 01.IJNS.03.02.72

10. M.M.Eusuff and K.E.Lansey,"Optimization of water distribution network desighn using the shuffled frog leaping algorithm,"J.water Resources Planning \& Management,vol.129(3),pp.210-225,2003

11. Vahid Rashtch1, Majid Kazemi1, Sasan Beheshti1, Optimal Design of Measurement-Type Current Transformer Using Shuffled Frog Leaping Algorithm, ACEEE Int. J. on Electrical and Power Engineering, Vol. 03, No. 02, May 2012, () 2012 ACEEE DOI: 01.IJEPE.03.02.

12. M. Eusuff, and K. Lansey, "Optimization of water distribution network design using the shuffled frog leaping algorithm," Journal of Water Resources Planning and Management, vol. 129, no. 2, pp., 210-25, 2003.

13. Y. Shi and R. Eberhart, "A modified particle swarm optimizer, "Proc Int. Conf. on Evolutionary Computation, Anchorage, AK, USA, pp. 69-73, 1998

14. Devender Singh, R. K. Misra, and Deependra Singh, "Effect of Load Models in Distributed Generation Planning," IEEE Transactions on Power Systems, Vol. 22, No. 4, pp.2204- 2212, November 2007

15. R. Ranjan and D. Das, "Voltage Stability Analysis of Radial Distribution Networks," Electric Power Components and Systems, Vol.31, pp.501- 511, 2003.

16. M. Chakravorty, D. Das, "Voltage stability analysis of radia distribution networks," Electric Power and Energy System, Vol.23, pp. 129-135, 2001.

17. Ulas Eminoglu and M. Hakan Hocaoglu,"A new power flow method for radial distribution systems including voltage dependent load models," Electric Power Systems Research, Vol.76, pp. 106-114, 2005

\section{AUTHORS PROFILE}

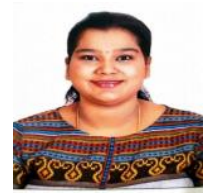

Mrs. Divya S., is a Research Scholar and completed her BE in the year 2009 in Electrical and Electronics Department. She received her M.tech degree in Powe Systems Engineering stream from National Institute of Engineering, Mysuru; during 2011. Her research area interest includes Power systems, Distributed generation, Power Quality, FACTS devices, Smart

Grids.

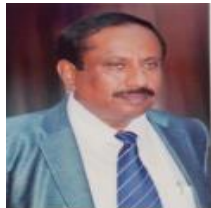

Dr. T. Anathapadmanabha, completed his BE in the year 1980 in Electrical and Electronics Department. He received his M.E degree in Power Systems Engineering stream during 1984 and was awarded with gold medal for securing $1^{\text {st }}$ rank. He completed his $\mathrm{PhD}$ in the year 1997 and again secured Gold Medal. Till date he has guided around

25 research scholars.

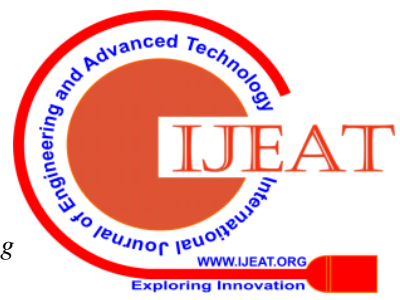


Dr. S. B. Shivakumar, completed his BE in Electrical and Electronics Department. He received his M.E degree in Power Systems Engineering stream. He was awarded with $\mathrm{PhD}$ degree from the National Institute of Engineering, Mysuru; $\mathrm{He}$ is guiding around 7 research scholars. Currently he is working as HOD (Electrical and Electronics) at RYMEC, Bellary. 